\title{
South Carolina Nonprofit Policies and Procedures: Achieving Best Practices for NPOs of Different Sizes
}

\author{
Karen A. Maguire ${ }^{1}$ \\ ${ }^{1}$ Department of Accounting, Coastal Carolina University, Conway, South Carolina, USA \\ Correspondence: Karen A. Maguire, Department of Accounting, Coastal Carolina University, Conway, South \\ Carolina, 29528 USA. Tel: 1-843-349-4163. E-mail: kmaguire@coastal.edu
}

Received: February 11, 2013 Accepted: April 1, 2013 Online Published: July 3, 2013

doi:10.5539/jms.v3n3p1 URL: http://dx.doi.org/10.5539/jms.v3n3p1

\begin{abstract}
The objective of this paper is to assemble a stepwise menu of policies and procedures for Nonprofit Organizations (NPOs) in South Carolina. This stepwise menu of policies and procedures will be used to assist NPOs of all sizes in South Carolina achieve best practices. Working in collaboration with The Chapin Foundation, The Waccamaw Community Foundation, and the South Carolina Association of Nonprofit Organizations (SCANPO), the output of this project will assist NPOs in obtaining affordable audits and reviews, utilizing cost-effective techniques when creating a policies and procedures manual, and adding to the policies and procedures manual as they grow. Achieving compliance with best practices for financial accountability, fundraising, and board governance, the output of this project facilitates the link between philanthropic leadership, charitable resources, and civic influence with community needs and opportunities.
\end{abstract}

Decision criteria in this analysis included the choice of Copedia's Non Profit Edition as a policies and procedures template library. Four sizes of NPOs were then chosen based primarily on SCANPO's membership categories, and secondarily on accounting method or Form 990 dollar size. Next, research was conducted to determine which policies were required by law. Finally, three sources of best practices for NPOs were employed to determine recommended policies for each of the four size categories. These included the following: SCANPO's Guiding Principles and Best Practices, third edition; the National Council of Nonprofits' and the Panel on the Nonprofit Sectors' Principles for Good Governance and Ethical Practice; and Blue Avocado's Five Internal Controls for the Very Small Nonprofit. This research was focused on giving a minimalist approach to the smallest category and slowly adding and integrating policies as the organization grows, with a culmination of all the policies being used in the largest category.

The research and analysis yielded the following results:

Using the assembled policies and procedures manuals in this paper, NPOs of all sizes can achieve best practices suggested by SCANPO's Guiding Principles and Best Practices, third edition; the National Council of Nonprofits' and the Panel on the Nonprofit Sectors' Principles for Good Governance and Ethical Practice; and Blue Avocado's Five Internal Controls for the Very Small Nonprofit.

22 policies are required by law for all NPOs, regardless of size.

34 policies are recommended for small NPOs. Combined with those required by law, the total number of policies that will allow a small NPO to achieve best practices without being encumbered by unnecessary polices is 56 .

65 policies are recommended for medium NPOs. Combined with those required by law, 87 policies will allow a medium NPO to achieve best practices.

87 policies are recommended for large NPOs. Combined with those required by law, 109 policies will allow a large NPO to achieve best practices.

102 policies are recommended for extra-large NPOs. Combined with those required by law, 124 policies will allow an extra-large NPO to achieve best practices.

The Unified Chart of Accounts (UCOA) is recommended for all firms. Smaller NPOs can utilize our recommended subset of UCOA accounts, then add accounts as they grow. UCOA provides instructions for existing NPOs to transition from their existing chart of accounts to UCOA. 
Keywords: Non-profit organizations, accounting, governance, policies and procedures, best practices

\section{Introduction}

The National Council of Nonprofits describes the significance of ethical leadership, accountability, and transparency for the nonprofit sector as follows:

"It is one thing to exist for the benefit of the public; it is another to earn the public's trust through ethical leadership and responsible practices. The good will earned by accountable and transparent nonprofits is one of, if not the most important, of its assets. Donors will give to organizations they trust to use their charitable gifts wisely. Volunteers will invest their time in causes when they trust that the nonprofit is acting ethically. And clients and consumers will return to a nonprofit for services, and recommend that nonprofit to others, when the nonprofit has shown to be accountable for its actions (National Council of Nonprofits 2012)."

The objective of this paper is to assemble a stepwise menu of policies and procedures for Nonprofit Organizations (NPOs) in South Carolina. This stepwise menu of policies and procedures will be used to assist NPOs of all sizes in South Carolina achieve best practices. Working in collaboration with The Chapin Foundation, The Waccamaw Foundation, and the South Carolina Association of Nonprofit Organizations (SCANPO), the output of this project will assist NPOs in obtaining affordable audits and reviews, utilizing cost-effective techniques when creating a policies and procedures manual, and adding to the policies and procedures manual as they grow. Achieving compliance with best practices for financial accountability, fundraising, and board governance, the output of this project facilitates the link between philanthropic leadership, charitable resources, and civic influence with community needs and opportunities.

In the Fall of 2011, the graduate Advanced Auditing class at Coastal Carolina University conducted a research service learning survey of South Carolina NPOs to gauge the overall knowledge of corporate governance, accounting, and auditing policies and to determine, what, if any, practices and programs these organizations currently have in place. The goal in compiling this data was to determine areas for improvement that will possibly lead to better and more efficient accounting and stewardship practices in the future. Two hundred forty-three NPOs responded over a two week period. Comments from all demographic segments indicated that South Carolina NPOs would be interested in more training regarding best practices and in obtaining resources to help them achieve best practices (Maguire 2012).

One of the survey questions asked South Carolina NPOs about their implementation of various formal policies and procedures. In the aggregate, an average of $54 \%$ of respondents have already implemented one or more practices while $21 \%$ planned to implement the practices and $16 \%$ have no plans to implement the practices (Maguire 2012). These include policies that are required by law. Open ended responses were solicited as well. Sample quotes from respondents include the following:

"The cost of financial reviews and preparation of the 990 tax return is extremely expensive to non-profit organizations."

"Make sure nonprofits are aware of best practices in finance and accounting and strive to better manage the organization's assets each year, whatever their budget."

"There could be a pool that nonprofits buy membership into that allows discounts for back office costs such as audits, marketing, purchasing, HR, legal, etc. (Maguire 2012)."

The first step in this project was to choose a policies and procedures manual template library. The template library must contain a set of policies and procedures that are integrated, customizable, target the highest level of corporate governance, and specifically address NPOs. The Non Profit Edition of the Copedia Content Library met each of these criteria (Copedia 2012). This will allow an NPO to purchase a license for the complete Copedia Non Profit Edition, and then assemble the policies and procedures manual that best fits their current needs. Since the NPO has a license for the complete Copedia manual, they can work with the class to add policies as their needs change. The current price for the Copedia Non Profit Edition is \$275 (Copedia 2012). Therefore, all policies, procedures, and policy ID numbers recommended in this project are those used in the Copedia Non Profit Edition.

The second step in this project was to define the NPO size categories. Four sizes of NPOs were chosen - Small, Medium, Large, and Extra-Large. The primary source used to define these categories is SCANPO's Nonprofit Membership categories (SCANPO 2012). SCANPO bases membership dues primarily on fulltime employee equivalents (FTEs). The four categories using SCANPO's FTEs are therefore:

Small NPO - Up to 2 FTEs 
Medium NPO -3 to 15 FTEs

Large NPO - 16-50 FTEs

Extra-Large NPO - 51+ FTEs

Some sections of the Copedia manual required a secondary size definition based upon dollars or accounting method to clarify category choices. When dollar size was employed, the current sizes as defined by the Form 990 Series were used (IRS 2011). Small NPOs were considered those that filed the Form 990-N and had gross receipts normally less than $\$ 50,000$. Medium NPOs were expected to file the Form 990-EZ with gross receipts less than $\$ 200,000$ and total assets less than $\$ 500,000$. Large NPOs would file the Form 990 with gross receipts greater than or equal to $\$ 200,000$ and total assets greater than or equal to $\$ 500,000$ (IRS 2011). When accounting method was needed to clarify a category choice, the assumption was made that small NPOs mainly utilized cash basis accounting methods, medium NPOs mainly utilized modified-accrual accounting methods, and large NPOs mainly utilized full-accrual accounting methods.

The third step in this project was to assign specific policies and procedures to NPOs of different sizes so that they achieved best practices. At the same time, the effort was made to avoid applying policies and procedures to smaller NPOs that would encumber them with policies that were too complex and that actually hindered their effective and efficient operation. Three sources of best practices were therefore employed: SCANPO's Guiding Principles and Best Practices, third edition; the National Council of Nonprofits' and the Panel on the Nonprofit Sector's Principles of Good Governance and Ethical Practice; and Blue Avocado's Five Internal Controls for the Very Small Nonprofit. Analysis of each section of the policies and procedures manual will address which best practices from these three sources are being followed. The completed policies and procedures manuals for all four sizes of NPOs succeed in addressing every best practice category for all three of these sources.

SCANPO's Guiding Principles and Best Practices, third edition are comprised of nine major guiding principles:

\section{Mission \& Strategic Direction}

Nonprofits engage in strategic thinking as a continuous process that drives organizational success. Board leadership thinks deliberately about its mission, values and vision, considering how to operate effectively, stay relevant and achieve sustainability.

\section{Governance}

Nonprofit boards govern by providing high-level vision and leadership to ensure sound stewardship of organizational assets and resources.

\section{Legal \& Ethical Accountability}

Nonprofits, by nature, exist to serve the public good. They are obligated to display high levels of ethical behavior, accountability, transparency and compliance with the law.

\section{Financial Management \& Stewardship}

Nonprofits effectively and responsibly manage the financial resources bestowed upon them and upon which they rely to accomplish their mission.

\section{Operations \& Evaluation}

Nonprofits develop, implement and monitor operational plans to ensure accountability, evaluation and continuous improvement.

\section{Human Resources}

Nonprofits recognize that people are their most important asset. They utilize effective leadership and fair practices to attract and retain employees and volunteers.

\section{Fundraising}

Nonprofits provide donors with ways to support the community, causes and organizations they value. As agents of philanthropy, nonprofits have an ethical and fiduciary obligation to handle funds appropriately, honor donors' wishes and have sufficient funds to carry out its mission.

\section{Marketing \& Communications}

Nonprofits engage in marketing that adheres to high ethical and professional standards to communicate the organization's mission, vision, values and progress toward social change to all stakeholders.

9. Information Management 
Nonprofits use secure technologies to maintain accurate information that informs decision-making (SCANPO 2012).

The best practices established by the National Council on Nonprofits and the Panel on the Nonprofit Sector are comprised of 33 principles categorized into four main categories:

1. Legal Compliance and Public Disclosure

Responsibilities and practices, such as implementing conflict of interest and whistleblower policies, that will assist charitable organizations in complying with their legal obligations and providing information to the public.

\section{Effective Governance}

Policies and procedures a board of directors should implement to fulfill its oversight and governance responsibilities effectively.

\section{Strong Financial Oversight}

Policies and procedures an organization should follow to ensure wise stewardship of charitable resources.

4. Responsible Fundraising

Policies and procedures organizations that solicit funds from the public should follow to build donor support and confidence (Panel on the Nonprofit Sector 2007).

Blue Avocado recommends Five Internal Controls for the Very Small Nonprofit as follows:

1. Set the control environment to let everyone know from the top down that there are policies in place and everyone has to follow the policies.

2. Define clearly who is responsible for what.

3. Have physical controls (such as locks, and passwords).

4. If there is cash involved then have two people count it.

5. Have the bookkeeping and bank reconciling functions separated (Ho 2010).

With the use of these three sources as well as other credible sources, the policies listed in the Copedia nonprofit policies and procedures manual were employed to comprise policy lists for our four categories. This research was focused on taking a minimalist approach to the smallest category and slowly adding and integrating policies as the organization grows, with a culmination of all the policies being used in the largest category.

The remainder of this paper is organized using the recommended table of contents for the policies and procedures manual provided by Copedia. Analysis within each category involves determining how to implement the policies for Small, Medium, Large, and Extra-Large NPOs. This process includes which policies, if any, are required by law, which of SCANPO's Guiding Principles and Best Practices apply, which categories and principles from the National Council of Nonprofits apply, and which of Blue Avocado's Five Internal Controls for the Very Small Nonprofit are addressed where applicable.

\section{Board of Directors and Governance}

Table 1. Board of directors and governance policies

\begin{tabular}{lllll}
\hline Policy ID & NPO Cat 1: & NPO Cat 2: & NPO Cat 3: & NPO Cat 4: \\
& Smallest & Medium & Large & Extra-Large \\
\hline Govern-100 & $\checkmark$ & $\checkmark$ & $\checkmark$ & $\checkmark$ \\
Board Policy & $\checkmark$ & $\checkmark$ & $\checkmark$ & $\checkmark$ \\
Govern-200 Budgeting & $\checkmark$ & $\checkmark$ & $\checkmark$ \\
Govern-300 Investment Policy & $\checkmark$ & $\checkmark$ & & \\
\hline
\end{tabular}

The Board of Directors is responsible for the leadership and control of the NPO, including strategic planning, budgeting, approvals of significant transactions, and annual reviews of the NPO's policies and procedures (Copedia 2012). All nine of SCANPO's Guiding Principles are affected by Board approved policies and procedures. However, the Governance Guiding Principle is directly related to the policies implemented in this section (SCANPO 2012). The same is true when considering the National Council of Nonprofits' Principles for Good Governance and Ethical Practice. All of the Principles are at the least indirectly affected by an NPO's Board decision making. However, the Effective Governance category is directly affected. This includes 
Principles 8-20, which describe what policies and procedures the Board should implement to fulfill its oversight and governance responsibilities (Panel on the Nonprofit Sector 2007). With respect to the Blue Avocado categories, this section directly applies to the Setting the Control Environment objective (Ho 2010).

Although there are only three policies directly related to the governance of an organization, each subsection of the policies deals with important and relevant aspects of the management and leadership of the organization. These policies cover a wide range of activities and operations. While the scope of each policy will differ slightly depending on the size of the nonprofit organization, each policy should be put in place even in the smallest organization. Therefore, we recommend that all NPOs regardless of size implement Govern-100 Board Policy, Govern-200 Budgeting, and Govern-300 Investment Policy.

While the Board of Directors and Governance section focuses more on the goal of policies rather than their implementation, it is important that NPOs of every size adopt all of these policies. This allows for the Board of Directors to provide leadership and management at the top of the organization and set the tone for how the organization functions and operates.

\section{Mission, Vision, and Planning}

Table 2. Mission, vision, and planning policies

\begin{tabular}{lllll}
\hline Policy ID & NPO Cat 1: & NPO Cat 2: & NPO Cat 3: & NPO Cat 4: \\
& Smallest & Medium & Large & Extra-Large \\
\hline Planning-100 Mission Statement & $\checkmark$ & $\checkmark$ & $\checkmark$ & $\checkmark$ \\
Planning-200 Business Plan & $\checkmark$ & $\checkmark$ & $\checkmark$ & $\checkmark$ \\
Planning-300 Strategic Plan & $\checkmark$ & $\checkmark$ & $\checkmark$ & $\checkmark$ \\
\hline
\end{tabular}

Policies that should be utilized by all NPOs are the establishment of a mission statement, business plan, and strategic plan. These three policies are important to the formation of NPOs as they are the framework for the entire organization. Therefore, we recommend that all NPOs regardless of size implement Planning-100 Mission Statement, Planning-200 Business Plan, and Planning-300 Strategic Plan.

The mission statement is found in the following three of SCANPO's Guiding Principles: Mission \& Strategic Direction, Legal \& Ethical Accountability, and Marketing \& Communications (SCANPO 2012). The importance of the mission is also stated in Principle 8, which addresses the review of mission and goals, found in the National Council for Nonprofits' Principles for Good Governance and Ethical Practice (Panel on the Nonprofit Sector 2007). The mission statement is vital to the purpose of the organization as it will indicate where or to whom the money will be distributed. As stated in Form 990, the IRS requires an organization to describe its board-approved mission. A change in mission or purpose may affect the organization's tax-exempt status. In addition, the mission statement is the guideline for restricted endowments as it ensures that the donations are used in accordance with the original donor's intent.

"All NPOs should implement a strategic plan that aligns with the organization's mission. The strategic plan should include the following: a strategic vision and mission that defines the position and mission of the organization, financial and organizational objectives, identify future challenges that may halt the strategic plan, and the actions and tactics that will be used to accomplish the organization's goals. Once the plan has been implemented, it is recommended the board or management monitor the plan to evaluate performance and identify any deviations from the plan (Carpenter 2008)."

According to the National Council of Nonprofits, every NPO's board should set strategic goals regularly and periodically review them. It is recommended that these strategic goals be in line with the vision and mission of the organization. The National Council of Nonprofits states that the board is responsible for the NPO's vision, mission, and the setting of policies and strategies that will allow the NPO to fulfill its charitable purpose (Panel on the Nonprofit Sector 2007).

According to Blue Avocado's Five Internal Controls for the Very Small Nonprofit, it is recommended that all small NPOs implement a mission statement, business plan, and a strategic plan as the basis for establishing a control environment (Ho 2010). The policies and procedures adopted by each NPO will revolve around the organization's mission and plans.

Although it is not required by law, it would be beneficial for allNPOs to create a business plan. This will give the NPO direction and help the organization strategize ways to grow and increase the amount of donations it 
receives. Smaller NPOs do not have to create an extensive plan, but at least should have general requirements and goals for the organization to provide direction. SCANPO also stresses the importance of a business plan in its Operations \& Evaluation Guiding Principle (SCANPO 2012). Creating plans that revolve around the NPO's mission and vision is the first step toward driving the organization in a particular direction.

\section{Administration and Conduct}

Table 3. Administration and conduct policies

\begin{tabular}{lllll}
\hline Policy ID & NPO Cat 1: & NPO Cat 2: & NPO Cat 3: & NPO Cat 4: \\
& Smallest & Medium & Large & Extra-Large \\
\hline Admin-100 Organizational Chart & $\checkmark$ & $\checkmark$ & $\checkmark$ & $\checkmark$ \\
Admin-200 Administrative Procedures & & $\checkmark$ & $\checkmark$ & $\checkmark$ \\
Admin-210 Telephone Procedures & & $\checkmark$ & $\checkmark$ & $\checkmark$ \\
Admin-220 Office Tasks & & & & $\checkmark$ \\
Admin-230 Crisis Management & & $\checkmark$ & $\checkmark$ & $\checkmark$ \\
Admin-300 Code of Ethics & $\checkmark$ & $\checkmark$ & $\checkmark$ & $\checkmark$ \\
Admin-310 Whistleblower & $\checkmark$ & $\checkmark$ & $\checkmark$ & $\checkmark$ \\
Admin-400 Fraud \& Embezzlement & $\checkmark$ & $\checkmark$ & $\checkmark$ & $\checkmark$ \\
Admin-410 Conflicts of Interest Policy & $\checkmark$ & $\checkmark$ & $\checkmark$ & $\checkmark$ \\
Admin-500 Delegated Authority & & $\checkmark$ & $\checkmark$ & $\checkmark$ \\
Admin-510 Division of Duties & & $\checkmark$ & $\checkmark$ & $\checkmark$ \\
\hline
\end{tabular}

Administration and Conduct Policies are necessary to establish employee standards and rules within the NPO. The NPO establishes these policies to ensure proper protocol is followed in all situations that may arise in the work place. Additionally, some of these policies are required by law and must be implemented by the company at inception. The implementation of these policies is meant to limit legal liability for the NPO as well as create a stable work environment for all employees and managers.

Under SCANPO's Guiding Principles \& Best Practices, the policies and procedures for administration and conduct fall under many different categories due to the variety within the section. These include Governance, Legal \& Ethical Accountability, Financial Management \& Stewardship, Operations \& Evaluation, and Marketing \& Communications. The administration and conduct policies also fall under the concepts and principles within the National Council for Nonprofits' Principles for Good Governance and Ethical Practice. Principles 1-5 in the Legal Compliance and Public Disclosure category and Principle 22 in the Strong Financial Oversight category all relate directly to specific administration and conduct policies. All five internal controls for very small nonprofits outlined by Blue Avocado can relate to the policies and procedures found within the administration and conduct section.

Two of the policies within administration and conduct are required by law. Admin-310 Whistleblowing Policy is required by the Sarbanes-Oxley Act, and this applies to both for-profit and not-for-profit organizations. According to Section 1107, it is a federal crime to retaliate against a whistleblower who reports legitimate suspected wrongdoing (Sarbanes-Oxley Act 2002). Also in the IRS Form 990, which is required for NPOs, it asks whether the organization has a written whistleblower policy (IRS 2011). Admin-410 Nonprofit Conflict of Interest Policy satisfies IRS requirements in the Form 990 and Form 1023, the latter of which is required to obtain tax-exempt status (IRS 2011). In addition, all states have statues that mandate a duty of loyalty for all officers and directors (National Council of Nonprofits 2007).

\section{Small NPOs}

According to Blue Avocado, a control environment must be established from the start. This environment is similar to what non-public companies call a "SOX-like environment," where private companies try to adhere to all of the Sections of The Sarbanes-Oxley Act to which public companies are subject. In order to establish this environment, the NPO must establish administration and conduct policies that comply with the laws as well as address all necessary procedures for initial operation of the NPO at inception. These policies include Admin-100 Organizational Chart, Admin-300 Code of Ethics Policy, Admin-310 Whistleblowing Policy, Admin-400 Fraud and Embezzlement Policy, and Admin-410 Nonprofit Conflict of Interest Policy. All of these policies are necessary to protect the company from legal liability as well as create a base level of procedures under which the NPO can operate. 


\section{Mediumand Large NPOs}

As the NPO continues to grow, additional policies must be implemented to establish control and procedures in different areas of the company. Additional employees mean division of duties as well as other administrative tasks that will become more relevant and will need to be addressed with specific policies. These policies include Admin-200 Administrative Procedures, Admin-210 Telephone Answering Procedures, Admin-230 Crisis Management, Admin-500 Delegated Authority Policy, and Admin-510 Division of Duties.

\section{Extra-Large NPOs}

No extra policies will be implemented until the NPO is defined as an extra-large sized NPO. Admin-220 Office Task List is recommended once the NPO grows to this size. A company that has more than 50 fulltime employees can begin todefine specifically the different office tasks each department will have to complete. Many of these office tasks will already have been completed before the organization reaches this size, but a list will help provide organization to the department and give them an exact list of what is required.

Establishing administrative and conduct policies are necessary to protect the NPO legally as well as establish a control environment. These policies will be implemented early in the NPO's life to ensure proper procedures are being followed throughout the organization's growth. Some of these policies are required by law, but all of these policies will directly and indirectly help the NPO operate more efficiently by establishing rules to follow for all employees in the organization.

\section{Accounting Overview}

Table 4. Accounting overview policies

\begin{tabular}{lllll}
\hline Policy ID & NPO Cat 1: & NPO Cat 2: & NPO Cat 3: & NPO Cat 4: \\
& Smallest & Medium & Large & Extra-Large \\
\hline Acct-100 Accounting Process Overview & $\checkmark$ & $\checkmark$ & $\checkmark$ & $\checkmark$ \\
Acct-150 Accounting Process Flowchart & $\checkmark$ & $\checkmark$ & $\checkmark$ & $\checkmark$ \\
Acct-190 Accounting Department Organization & $\checkmark$ & $\checkmark$ & $\checkmark$ & $\checkmark$ \\
Acct-200 Accounting System Description & $\checkmark$ & $\checkmark$ & $\checkmark$ & $\checkmark$ \\
Acct-300 Responsibilities and Job Descriptions & $\checkmark$ & $\checkmark$ & $\checkmark$ & $\checkmark$ \\
Acct-400 Chart of Accounts & $\checkmark$ & $\checkmark$ & $\checkmark$ & $\checkmark$ \\
Acct-500 Capturing Economic Events & $\checkmark$ & $\checkmark$ & $\checkmark$ & $\checkmark$ \\
\hline
\end{tabular}

All of the policies in the accounting manual and overview are recommended for NPOs of all sizes. While not every policy in this manual will be fully integrated by the smallest NPOs, it does provide a basic set of accounting procedures that will guide the NPO in its growth and proper financial reporting. As suggested in the Blue Avocado article, board members of small NPOs will need to take a greater role in order to provide necessary controls. For example, a board member may need to receive the unopened bank statement and complete the reconciliation to provide a check on those handling the cash (Ho 2010).

These policies are also recommended based on the results of the survey of NPOs in South Carolina. According to the survey, $51 \%$ of respondents use an online accounting system and $38 \%$ plan to implement one. Of the $51 \%$ that are currently using one, 28\% are using Intuit QuickBooks NFP and 7\% are using Blackbaud's The Financial Edge (Maguire 2012). Furthermore, these two accounting systems are compatible with the Unified Chart of Accounts (UCOA), which is also recommended later in this paper to achieve best practices.

The recommended policies fall under SCANPO's Guiding Principles Legal \& Ethical Accountability and Financial Management \& Stewardship (SCANPO 2012). These policies also are included in the National Council for Nonprofits' Strong Financial Oversight category, specifically Principles 21, 22, and 24 (Panel on the Nonprofit Sector 2007). In addition, these policies relate to all five recommendations that are detailed in the Blue Avocado article(Ho 2010).

The following policies are recommended regardless of size or method of accounting, but should be adjusted based on the individual needs of the NPO.

Acct-100 Accounting Process Overview describes the basics of accounting. It includes revenues, expenses, assets, liabilities, and owners' equity as well as how to record them and how they flow into financial statements. It also explains accrual accounting.

Acct-150 Accounting Process Flowchart helps determine how normal operating transactions flow through an 
accounting system from input to financial statements.

Acct-190 Accounting Department Organization defines the different groups of accounting such as payroll, receivables, and payables as well as the role of the controller in the accounting department.

Acct-200 Accounting System Description describes the type of accounting system that the NPO uses.

Acct-300 Responsibilities and Job Description explains the responsibilities of anyone involved in the accounting process.

Acct-400 Chart of Accounts lists all accounts that are used within the organization's accounting software. It should also include an account dictionary that describes each account and what it is used for, as well as any other necessary information.

Acct-500 Capturing Economic Events provides resources to learn about revenue, expenses, and the matching principle.

\section{Unified Chart of Accounts}

The Unified Chart of Accounts (UCOA) is a free chart of accounts that is designed specifically for NPOs. It allows for the NPO to quickly and reliably translate their financial statements into categories which are required by IRS Form 990, the Federal Office of Management and Budget (OMB), and other reporting formats.

Based on the 2011 Study of Non-Profits Organizations in South Carolina, 78\% of respondents conduct a Form 990 Review and another $9 \%$ plan to implement such. 36\% of respondents utilize UCOA in their financial accounting, and another $15 \%$ plan to implement it. $38 \%$ of the NPOs do not currently have an online accounting system, but plan to implement one in the future. UCOA is compatible with both the Form 990 and two of the most utilized online accounting systems reported in the survey, Intuit QuickBooks NFP and Blackbaud's The Financial Edge (Maguire 2012).

UCOA implementation falls under SCANPO's Guiding Principles Financial Management \& Stewardship and Information Management (SCANPO 2012). UCOA also relates to the National Council of Nonprofits' Strong Financial Oversight and its related principles (Panel on the Nonprofit Sector 2007). Finally, UCOA addresses setting the Control Environment, one of the five internal controlswithin the Blue Avocado guidelines (Ho 2010).

UCOA is recommended for NPOs of all sizes. Aset of recommended UCOA charts of accounts, broken down by the size of the NPO, is available from the author by request. The accounts chosen are based on their relevance to the accounting and operational needs of each size. The recommended charts of accounts are set up using modified accrual accounting method for small and medium size NPOs and the accrual method for large and extra-large NPOs. Recognizing that small and medium NPOs may use the cash method instead of the modified accrual method, the removal of accounts receivable and accounts payable from the recommended chart of accounts is suggested to handle this change. Some accounts were included in all sizes and changes may need to be made on an individual basis. The creators of UCOA also provide free resources that demonstrate to NPOs already in operation how to translate their existing chart of accounting into the UCOA format. Appendix A contains a list of resources available to NPOs who opt to implement UCOA, including how to request the set of recommended UCOA charts of accounts. UCOA is a useful tool to connect the Form 990 preparation and review to NPOs' online accounting systems.

\section{Assets}

Table 5. Assets policies

\begin{tabular}{lllll}
\hline Policy ID & NPO Cat 1: & NPO Cat 2: & NPO Cat 3: & NPO Cat 4: \\
& Smallest & Medium & Large & Extra-Large \\
\hline Assets-100 Accounting for Assets & $\checkmark$ & $\checkmark$ & $\checkmark$ & $\checkmark$ \\
Assets-120 Capital Expenditures & & $\checkmark$ & $\checkmark$ & $\checkmark$ \\
Assets-200 Petty Cash & & $\checkmark$ & $\checkmark$ & $\checkmark$ \\
Assets-400 Cash Best Practices & & $\checkmark$ & $\checkmark$ & $\checkmark$ \\
Assets-410 Cash Management & $\checkmark$ & $\checkmark$ & $\checkmark$ & $\checkmark$ \\
Assets-700 Asset Disposal & & & $\checkmark$ & $\checkmark$ \\
Assets-710 Asset Disposal Methods & & & $\checkmark$ & $\checkmark$ \\
\hline
\end{tabular}

Best practices recommend that policies and procedures be in place to safeguard an NPO's financial assets, and to make certain that more than one person is responsible for managing the funds of the organization. Under 
SCANPO's Guiding Principles, assets fall under Financial Management \& Stewardship. This principle advises NPOs to responsibly handle the financial resources they are given. Assets fall into two of the National Council of Nonprofits' categories. The first is Legal Compliance and Public Disclosure, where Principle 7 applies. The second is Strong Financial Oversight, where Principle 22 applies.

\section{Small NPOs}

The smallest category NPO should have policies that address the requirements from Blue Avocado's Five Internal Controls for the Very Small Nonprofit. The first policy regarding assets that should be implemented is Assets-100 Accounting for Assets. Accounting for assets is an important policy to have at any size NPO because assets need to be reported correctly on the balance sheet. This is also a crucial policy because financial statements are legally required, which is addressed in the Financial Reporting section. One of the topics included in this policy that coincides with the Blue Avocado article is physical controls to protect company assets. For example, checks should be locked up to decrease the risk of theft. There are internal control policies that go into greater detail that are implemented at the higher NPO categories. Division of duties is included in this policy, but with only two full time employees at most, it is nearly impossible to do in this size NPO. At a minimum, a board member should reconcile the unopened bank statement. This will reduce the risk of embezzlement by any of the employees who handle the money. Based on the Blue Avocado article, another policy that should be implemented is Assets-410 Cash Management. A policy regarding cash provides methods to keep track of cash receipts and payments. If there is a cash policy in place, it will help minimize the risk of theft or fraud. For example, cash should always be locked up, and cash should be deposited daily to prevent theft. If possible in the small size NPO, a different person should do cash handling than that doing cash accounting. Given that asset misappropriations are the most common form of occupational fraud, these two policies should be implemented at every size NPO to assist in preventing fraud (Albrecht 2012).

\section{MediumNPOs}

The medium NPO category includes all of the policies in the smallest NPO category plus some additional ones that provide more complex policies. The ones added are: Assets-120 Capital Expenditures, Assets-200 Petty Cash, and Assets-400 Cash Best Practices. According to Nonprofit Accounting Basics, fixed asset policies are implemented at a medium size organization (O'Malley 2009). Fixed assets should always be approved prior to acquiring. Assets-200 Petty Cash is used for small purchases. Petty cash is also included in the Assets-410 Cash Management policy, which is implemented at the small NPO category. The standalone petty cash policy is more elaborate and well suited to be implemented at this size NPO. We recommend that Assets-400 Cash Best Practices be implemented at the medium Size NPO as well. This is a detailed listing of procedures that are also included in the Assets-410 Cash Management policy implemented earlier.

\section{Large and Extra-Large NPOs}

The large and extra-large size categories include all of the policies in the Small and Medium size categories plus Assets-700 Asset Disposal and Assets-710 Asset Disposal Methods. These policies are used when assets are no longer necessary or have outlived their useful lives. They describe when assets need to be disposed of and how to dispose of them properly.

\section{Liabilities}

Table 6. Liabilities policy

\begin{tabular}{lllll}
\hline Policy ID & $\begin{array}{l}\text { NPO Cat 1: } \\
\text { Smallest }\end{array}$ & $\begin{array}{l}\text { NPO Cat 2: } \\
\text { Medium }\end{array}$ & $\begin{array}{l}\text { NPO Cat 3: } \\
\text { Large }\end{array}$ & $\begin{array}{l}\text { NPO Cat 4: } \\
\text { Extra-Large }\end{array}$ \\
\hline Liabilities-100 & $\checkmark$ & $\checkmark$ & $\checkmark$ & $\checkmark$ \\
Accounting for Liabilities & $\checkmark$ & $\checkmark$ & $\checkmark$ & $\checkmark$ \\
\hline
\end{tabular}

SCANPO's Guiding Principle for Financial Management \& Stewardship speaks to the need for NPOs to use their financial resources effectively and responsibly (SCANPO 2012).This coupled with the National Council of Nonprofits' Principle 21 on Strong Financial Oversight supports our recommendation that a strong policy on accounting for liabilities be adopted at the smallest NPO level and carried forward through the larger NPO sizes (Panel on the Nonprofit Sector 2007).

Consistent and thorough accounting for liabilities is crucial at any size of organization. Establishing good fiscal policies and procedures is more of an investment of time and attention than money. Very few small nonprofits or 
all-volunteer groups can commit to the conversations and documentation needed to establish sound financial policies (Compass Point 2012). Regardless, proper accounting for liabilities will be essential in developing mandatory financial statements and accurate internal reports.

Liabilities-100 Accounting for Liabilities is recommended for all NPOs, regardless of size. Although each NPO will have its own varying complexities, the valuation and reporting of liability accounts should be consistent across all NPO sizes.

\section{Financial Reporting}

Table 7. Financial reporting policies

\begin{tabular}{|c|c|c|c|c|}
\hline Policy ID & $\begin{array}{l}\text { NPO Cat 1: } \\
\text { Smallest }\end{array}$ & NPO Cat 2: Medium & $\begin{array}{l}\text { NPO Cat 3: } \\
\text { Large }\end{array}$ & $\begin{array}{l}\text { NPO Cat 4: } \\
\text { Extra-Large }\end{array}$ \\
\hline Finance-100 Journal Entry & $\checkmark$ & $\checkmark$ & $\checkmark$ & $\checkmark$ \\
\hline $\begin{array}{l}\text { Finance-200 Financial } \\
\text { Reporting }\end{array}$ & $\checkmark$ & $\checkmark$ & $\checkmark$ & $\checkmark$ \\
\hline $\begin{array}{l}\text { Finance-300 Financial } \\
\text { Analysis }\end{array}$ & & $\begin{array}{l}\checkmark \text { Expanded as } \\
\text { Organization grows }\end{array}$ & $\begin{array}{l}\checkmark \text { Expanded as } \\
\text { Organization grows }\end{array}$ & $\begin{array}{l}\checkmark \text { Use of } \\
\text { complete Policy }\end{array}$ \\
\hline $\begin{array}{l}\text { Analysis } \\
\text { Finance-400 }\end{array}$ & & $\checkmark$ Expanded as & $\checkmark$ Expanded as & $\checkmark$ Use of \\
\hline Benchmarking & & Organization grows & Organization grows & complete Policy \\
\hline
\end{tabular}

According to the Study on Non-Profit Organizations in South Carolina, 51\% of survey respondents currently use an online accounting system, and an additional $38 \%$ plan to implement such a system. In addition, more than half of the respondents are seeking non-grant revenue sources to fund operating expenses. The study also indicates that $94 \%$ of respondents have or will be communicating the impact of programs to stakeholders and $92 \%$ have or will be communicating how donations are spent (Maguire, 2012).

The need for financial reporting policies is reflected in SCANPO's Guiding Principles Legal \& Ethical Accountability, Financial Management \& Stewardship, and Operations \& Evaluation (SCANPO 2012). In addition, the National Council of Nonprofits' Principles $1 \& 7$ on Legal Compliance \& Public Disclosure and Principle 21 regarding Strong Financial Oversight are applicable for financial reporting policies (Panel on the Non Profit Sector 2007). Furthermore, the Blue Avocado's Five Internal Controls for the Very Small Nonprofit speaks to the need to Set the Control Environment and to Reconcile the Bank Statement (Ho 2010).

It is easy to see why SCANPO, the National Council for Nonprofits, and Blue Avocado express the need for strong financial reporting. Many facets of financial reporting are required for Generally Accepted Accounting Principles (GAAP) and by law (IRS 2011). In addition, improper filing could result in revocation of Tax Exempt Status (Blackwood \& Roeger 2012).

The Financial Accounting Standards Board's (FASB) objectives of financial reporting for NPOs include making resource allocation decisions; assessing services and ability to provide service; assessing management stewardship and performance; and assessing economic resource, obligations, net resources, and changes in them. FASB ASC 958-205-45-4 requires, as a minimum, that NPOs present a statement of financial position, a statement of activities and a statement of cash flows that present financial information for the entity as a whole (Blackwood \& Roeger 2012).

\section{Small NPOs}

To ensure compliance with applicable laws (IRS 2011), our recommendation for small NPOs is to implement Finance-100 Accounting Journal Entry Procedure and Finance-200 Financial Reporting Policy. These policies standardize how journal entries and accounting ledgers are updated and by whom. In addition, with these policies small NPOs will begin to implement a policy that clarifies which reports will be generated, when they will be generated and how they will be generated. Such reports may consist of internal reports for management as well as mandatory financial statements required under GAAP. Recognizing that the reporting needs for a small NPO will vary greatly from that of an extra-large NPO, a gradual implementation of Finance-200 Financial Reporting Policy is recommended that starts with the required minimum reporting at the small NPO level and builds out the policy to full implementation at the extra-large size NPO.

\section{Medium, Large, and Extra-Large NPOs}

The second layer of the recommendation would be to implement policies on how the NPO will measure its 
successes and failures against itself and industry peers with the use of financial analysis and benchmarking. Implementing Finance-300 Financial Analysis and Finance-400 Benchmarking is recommended at the medium NPO size. Again, this would not be a full implementation of the policy, but a graduated implementation across NPO sizes. Financial Analysis and Benchmarking provides invaluable information to stakeholders and management. However, it should be recognized that these tasks can be costly and time consuming and the information that they provide should be balanced with the time and man-hours they take to generate. The need for expanded analysis will grow over time with the organization. It is recommended that medium sized NPOs start with financial analysis that measures liquidity; the ability for the organization to maintain as a going concern; program effectiveness and efficiency; leverage and debt coverage; and fundraising efficiency.

\section{Revenue}

Table 8. Revenue policies

\begin{tabular}{lllll}
\hline Policy ID & NPO Cat 1: & NPO Cat 2: & NPO Cat 3: & NPO Cat 4: \\
& Smallest & Medium & Large & Extra-Large \\
\hline REV-100 Revenue Cycle Flowchart & & $\checkmark$ & $\checkmark$ & $\checkmark$ \\
REV-200 Account for Revenue & $\checkmark$ & $\checkmark$ & $\checkmark$ & $\checkmark$ \\
REV-210 Accounting for Gifts \& Endowments & & $\checkmark$ & $\checkmark$ & $\checkmark$ \\
REV-220 Grants and Contracts & & & $\checkmark$ \\
Rev-230 Church Offerings & & & $\checkmark$ \\
REV-245 Donor Records and Receipts & & & $\checkmark$ & $\checkmark$ \\
REV-250 Accounting for Receipts and Deposits & & & $\checkmark$ & $\checkmark$ \\
Rev-270 Returned Checks & & & & $\checkmark$ \\
\hline
\end{tabular}

Revenue policies provide guidelines for both operating and non-operating revenue, including revenue recognition policies and accounting for gifts and endowments. More than half of respondents in the South Carolina Study on Non-Profit Organizations reported that in the previous 12 months they sought non-grant revenue sources to fund operating expenditures, sought foundation grants for operating expenditures, and specifically solicited unrestricted gifts (Maguire 2012).

The revenue policies address SCANPO's Guiding Principles and Best Practices Legal \& Ethical Accountability, Financial Management \& Stewardship, and Operations \& Evaluation (SCANPO 2012). These policies relate to the Strong Financial Oversight section within the National Council of Nonprofits' best practices, specifically Principle 21 (Panel on the Nonprofit Sector 2007). In addition, the Cash section of the Blue Avocado controls applies when the revenue recognized involves cash (Ho 2010).

\section{Small NPOs}

The IRS mandates all revenue should be recognized when earned or realizable (IRS 2011).Rev-200 Accounting for Revenue focuses oninitial revenue recognition. It states that revenue should be recognized when it is earned, along with other policy information on revenue recognition. The NPO must comply with all laws and regulations; therefore the implementation of Rev-200 Accounting for Revenue is necessary at the inception of the NPO.

\section{Medium NPOs}

Medium NPOs require two more additional policies, which are Rev-100 Revenue Cycle Flowchart and REV-210 Accounting for Gifts and Endowments. These policies will be implemented as the size of the organization grows and the likelihood of soliciting gifts and endowments increases. The Revenue Cycle Flowchart will illustrate to the NPO employees how to collect and record the new and different types of revenues.

\section{Large NPOs}

In addition to the three policies already used, the large NPO segment will use two more policies, which are Rev-250 Accounting for Receipts and Deposits and Rev-270 Accounting for Returned Checks. As an NPO increases in size, more sophisticated methods for processing and controlling these functions are needed. Both policies provide specific procedures to follow when a situation arises in the particular category. Therefore, these policies supplement cash and revenue policies that are already in place for smaller NPOs.

\section{Extra-Large NPOs}

An extra-large NPOwill potentially use the final three revenue policies that are provided by Copedia. All three of these policies will only be used in specific situations. Rev-220 Accounting for Grants and Contracts focuses on 
controls and procedures when dealing with a grant or contract. Rev-230 Church Offerings addresses the recording of church offerings and allowable transactions between the church and its congregation. The last policy, Rev-245 Donor Records and Receipts, applies only to NPOs that qualify to receive deductible contributions as defined in IRS Publications 526 and 1771.

\section{Accounts Receivable}

Table 9. Accounts receivable policies

\begin{tabular}{lllll}
\hline Policy ID & $\begin{array}{l}\text { NPO Cat 1: } \\
\text { Smallest }\end{array}$ & $\begin{array}{l}\text { NPO Cat 2: } \\
\text { Medium }\end{array}$ & $\begin{array}{l}\text { NPO Cat 3: } \\
\text { Large }\end{array}$ & $\begin{array}{l}\text { NPO Cat 4: } \\
\text { Extra-Large }\end{array}$ \\
\hline Rev-AR-100 Accounts Receivable Policy & & $\checkmark$ & $\checkmark$ & $\checkmark$ \\
Rev-AR-200 Accounts Receivable Credit & & & & $\checkmark$ \\
Rev-AR-250 Credit Limit Calculator & & & & $\checkmark$ \\
Rev-AR-270 Credit Application & & & $\checkmark$ & $\checkmark$ \\
Rev-AR-300 AR Collections & & & $\checkmark$ & $\checkmark$ \\
Rev-AR-350 AR Lost Payments & & & $\checkmark$ & $\checkmark$ \\
Rev-AR-400 Bad Debt Write Off Flowchart & & & & \\
\hline
\end{tabular}

Accounts receivable policies relate to effectively managing moneys owed to the organization. These policies relate to SCANPO's Financial Management \& Stewardship and Operations \& Evaluation Guiding Principles (SCANPO 2012). With respect to the National Council of Nonprofits, receivables are addressed in the Strong Financial Oversight category, specifically Principle 21 (Panel on the Nonprofit Sector 2007). Receivables fall into the Blue Avocado Cash category (Ho 2010). NPOs must manage funds appropriately and these receivables policies establish clear guidelines to allow NPOs to operate effectively.

\section{Medium NPOS}

The accounts receivable policies begin in the medium size sector. The smallest sized NPOs already utilize Assets-410 Cash Management, which contains basic controls for accounts receivable. Medium NPOs are again defined as using the modified-accrual basis which allows for accounts receivable. The sole policy in the medium category is Rev-AR-100 Accounts Receivable Policy. This policy is an overview of accounts receivable and contains basic controls, procedures and division of duties that should be followed when an accounts receivable account is in place.

Large NPOS

Large NPOs will adopt three more policies regarding account receivables. As the company grows in size, the receivables balance will also increase and its management will become more complex. As the account grows additional polices become necessary, including policies that address collections and procedures for dealing with lost payments. These policies include Rev-AR- 300 Accounts Receivable Collections, Rev-AR- 350 Lost Payment Procedure, and Rev-AR-400 Bad Debt Write Off Flowchart. Each of these policies will establish procedures to maintain control and stability of receivables at a large NPO.

\section{Extra- Large NPOs}

For extra-large NPOs, it is useful to use the following policies before having their customers pay on credit. Using these three policies will enable the NPO to use an efficient plan in developing the guidelines for a customer's credit. The extra-large sized NPO's will use the final three policies Rev-AR-200 Accounts Receivable Credit, Rev-AR- 250 Credit Limit Calculator, and Rev-AR-270 Credit Application.

The proper management of accounts receivable is extremely important for the company to collect revenue to continue future operations. Initially a general accounts receivable policy must be established to address all the basic functions and controls of this account. The receivables account will continue to become more sophisticated as the company grows in size and monetary value. Additional policies will be gradually implemented as larger collections occur, and credit lines are established with customers. 


\section{Accounts Payable}

Table 10. Accounts payable policies

\begin{tabular}{lllll}
\hline Policy ID & NPO Cat 1: & NPO Cat 2: & NPO Cat 3: & NPO Cat 4: \\
& Smallest & Medium & Large & Extra-Large \\
\hline AP-100 - Accounts Payable Policy & & $\checkmark$ & $\checkmark$ & $\checkmark$ \\
AP-200 - Accounts Payable Procedures & & $\checkmark$ & $\checkmark$ & $\checkmark$ \\
AP-300 - Disbursement Approval Procedure Form & & $\checkmark$ & $\checkmark$ & $\checkmark$ \\
AP-350 - Accounting for Expenses & & $\checkmark$ & $\checkmark$ & $\checkmark$ \\
\hline
\end{tabular}

Accounts Payable polices relate to the issuance of payments for company obligations, and the safeguarding of the associated assets (Copedia 2012). These policies are in accordance with SCANPO's Guiding Principles Legal \& Ethical Accountability and Financial Management \& Stewardship (SCANPO 2012). Accounts payable and cash disbursements involve paying bills. The recommended SCANPO Guiding Principles encourage the NPO to pay the right person or vendor the correct amount, and protect payment information such as bank account and credit card numbers. The NPO should also pay attention to who is receiving their money and accurately keep track of such.

The recommended policies relate to the National Council of Nonprofits' Legal Compliance and Public Disclosure Principles 1, 2, and 6; and Strong Financial Oversight Principles 21, 24, 25, and 26 (Panel on the Nonprofit Sector 2007). These principles reiterate SCANPO's Guiding Principles that are mentioned above. Additionally, they fall within Blue Avocado's guidelines of Setting the Control Environment and Physical Controls (Ho 2010). All three sets of best practices suggest that an NPO let everyone involved in the NPO know that there are controls in place and everyone must follow them.

\section{Small NPOs}

Small NPOs are able to address payables with the cash and protection of asset policies chosen for small NPOs in the Assets section, namely Assets-100 Accounting for Assets and Assets-410 Cash Management.

\section{Medium NPOS}

For medium NPOs, we recommend AP-100 Accounts Payable Policy, AP-200 Accounts Payable Procedures, and AP-350 Accounting for Expenses. The AP-100 Accounts Payable policy is recommended at this level because it provides for guidelines on items that occur in the course of establishing an accounts payable department. We feel that it can be implemented at the medium size NPO because it is low cost yet provides valuable structure that is necessary when involving more than two employees.AP-200 Accounts Payable Procedures provides for consistent procedures in handling invoices and the issuance of checks, including the segregation of duties. AP-350 Accounting for Expenses policy provides guidelines on operating expenses and credits.

\section{Large and Extra-Large NPOs}

AP-300 Disbursement Approval Procedure sets controls on the authorization of various expenses. An example of how to do this is provided in the form of a table within the Accounts Payable Manual. This policy also details a vendor payment process flowchart to provide visual guidance in this area. This procedure is recommended for large and extra-large NPOs because it provides more detailed controls and policies that are necessary for these NPOs. These policies can be customized to fit with the accounts payable structure of the NPO.

\section{Purchasing and Receiving}

Table 11. Purchasing and receiving policies

\begin{tabular}{lllll}
\hline Policy ID & NPO Cat 1: & NPO Cat 2: & NPO Cat 3: & NPO Cat 4: \\
& Smallest & Medium & Large & Extra-Large \\
\hline Purch-100 Purchasing Policy and Procedures & $\checkmark$ & $\checkmark$ & $\checkmark$ & $\checkmark$ \\
Purch-150 Purchasing Flowchart & & $\checkmark$ & $\checkmark$ & $\checkmark$ \\
Purch-200 Purchase Order Policy & & $\checkmark$ & $\checkmark$ & $\checkmark$ \\
Purch-300 P-Card Policies and Procedures & & & $\checkmark$ & $\checkmark$ \\
Purch-400 Procurement Policy & & $\checkmark$ & $\checkmark$ \\
Receive-100 Receiving Inspecting & & $\checkmark$ & $\checkmark$ & $\checkmark$ \\
Warehousing & & $\checkmark$ & & \\
Receive-110 Receiving Flowchart & & & $\checkmark$ \\
\hline
\end{tabular}


According to Copedia, purchasing involves how an NPO buys goods, services, and assets. Receiving relates to the receipt, inspection, rejection, and warehousing of these purchased goods (Copedia 2012). When addressing these policies, the number of employees as well as the dollar size must be taken into account. For this reason one of our additional, secondary decision criteria was employed, the current size of the NPOs as defined by the Form 990 size categories (IRS 2011).

Two of SCANPO's Guiding Principles and Best Practices apply, Financial Management \& Stewardship and Operations \& Evaluation (SCANPO 2012). Principles 25 and 26 in the Strong Financial Oversight category apply with respect to the National Council of Nonprofit's Principles of Good Governance and Ethical Practice (Panel on the Nonprofit Sector 2007). Three of the Blue Avocado sections apply, namely Define Who is Responsible for What, Physical Controls, and Cash (Ho 2010).

\section{Small NPOs}

The small category is categorized by up to two FTE employees and gross receipts less than $\$ 50,000$ dollars. At this point in the NPO's life, the NPO is going to be making mostly small purchases and only needs a general purchasing policy in place. Some of these procedures will include quoting prices, p-cards, and division of duties. Purch-100 Purchasing Policies and Procedures contains general rules and guidelines that will allow small NPOs to operate effectively while still operating with basic internal controls.

\section{Medium NPOs}

As the NPO grows in size and gross receipts, additional policies must be put in place to continue to operate efficiently and minimize liability and risk. Within the medium category, Form 990 gross receipts are less than $\$ 200,000$, total assets are less than $\$ 500,000$, and employee numbers increases to 3-15 FTEs. In this range, the NPO will introduce flowcharts in Purch-150 Flowchart Purchasing and Receive-110 Flowchart Receiving which help visually show the proper protocol for all purchases and receipts. Due to increased employment in the medium category, it is important to maintain proper controls with increased values of the purchases and receipts. The NPO will be dealing with larger purchases orders in the medium category, which is why we also recommended implementing Purch-200 Purchase Order Policy and Receive-100 Receiving Inspecting Warehousing Policy at the medium NPO category.

\section{Large and Extra-Large NPOs}

At the large level, Form 990 gross receipts are greater than or equal to $\$ 200,000$, or total assets are greater than or equal to $\$ 500,000$. Sixteen or more FTEs are employed at the NPO. At this stage, the NPO should implement all policies dealing with purchasing and receiving. The NPO will be making larger purchases and have multiple employees that will independently make purchases on their own. Travel and reimbursements will also need proper accounting. Due to the increased risk of theft and abuse of NPO funds, we recommend Purchasing-300 P-Card Policies and Procedures and Purchasing-400 Procurement Policy be implemented at this level. Both of these policies supplement basic policies implemented earlier. After the implementation of these two polices, all of the purchasing and receiving policies will be utilized.

Purchasing and receiving is a vital activity for all NPOs. The fundamental policies will be established in the small NPOs. As the NPO grows, the additional policies will be implemented as employee number and gross receipts increase. The purpose of these policies is to help establish controls that will allow the NPO run its business efficiently and effectively, while protecting itself from risk of theft and employee abuse of funds.

\section{Records Management}

Table 12. Records management policies

\begin{tabular}{lllll}
\hline Policy ID & $\begin{array}{l}\text { NPO Cat 1: } \\
\text { Smallest }\end{array}$ & $\begin{array}{l}\text { NPO Cat 2: } \\
\text { Medium }\end{array}$ & $\begin{array}{l}\text { NPO Cat 3: } \\
\text { Large }\end{array}$ & $\begin{array}{l}\text { NPO Cat 4: } \\
\text { Extra-Large }\end{array}$ \\
\hline $\begin{array}{l}\text { Records-100 } \\
\text { Records Management Policy }\end{array}$ & $\checkmark$ & $\checkmark$ & $\checkmark$ & $\checkmark$ \\
$\begin{array}{l}\text { Records-200 } \\
\text { RecordkeepingProcedures }\end{array}$ & $\checkmark$ & $\checkmark$ & $\checkmark$ & $\checkmark$ \\
$\begin{array}{l}\text { Records-300 } \\
\begin{array}{l}\text { Records \& Files Cutoff Procedures } \\
\text { Records-400 }\end{array}\end{array}$ & $\checkmark$ & $\checkmark$ & $\checkmark$ \\
$\begin{array}{l}\text { Records Schedule } \\
\text { Records-500 }\end{array}$ & & & $\checkmark$ & $\checkmark$ \\
Record Series & & & $\checkmark$ & $\checkmark$ \\
\hline
\end{tabular}


Records Management policies and procedures address the handling of files by the NPO. The Study on Non-Profit Organizations in South Carolina was referenced for insight on policy recommendation. Respondents of the study indicated a need to expand revenue to non-grant revenue sources. They also indicated a desire to communicate to stakeholders the impact on programs and how donations are spent in an efficient manner. These responses indicate a need for strong Records Management policies to be in place. In addition, $61 \%$ of respondents to the survey have had an audit performed by an independent auditor (Maguire 2012). A sound records management policy would support NPOs as they seek a positive outcome for each of these goals.

Records Management continues to be a topic of best practices by both SCANPO and the National Council of Nonprofits. SCANPO's Guiding Principles on Legal \& Ethical Accountability, Financial Management \& Stewardship, and Information Management all speak to the need to have a records management policy program in place. The National Council of Nonprofits' Principles 5 and 6 regarding Legal Compliance \& Public Disclosure and Principle 21 regarding Strong Financial Oversight support strong records management practices (Panel on the Nonprofit Sector 2007).The Blue Avocado article highlights the need for a records management policy by stating the need to Set the Control Environment and the need to Define clearly who is responsible for what (Ho 2010).

\section{Small NPOs}

NPOs of all sizes have to maintain and organize important documents. Whether the need stems from compliance issues or the desire of management, it is recommended that small NPOs implement Records- 100 Records Management Policy and Records-200 Recordkeeping Procedures policy to build a strong foundation for future growth. The first policy outlines responsibilities for creating, maintaining, disposing, and archiving important documents. The second policy defines what records will be maintained, where they will be filed, and how the files themselves will be categorized. Consistency, security, and compliance should be the focus when developing such policies. Having a strong records management policy in place will help maintain best practices and compliance with various laws such as the Privacy Act of 1974 and HIPAA when applicable, for example during the hiring process.

\section{Medium NPOs}

For medium NPOs, the implementation of Records-300 Records \& Files Cutoff Procedures is recommended. This policy contains procedures to manage the size and status of files.

Large and Extra-Large NPOs

For the large and extra-large NPOs, Records-400 Records Schedule and Records-500 Record Series policies are recommended. These policies allow for more sophisticated record management systems.

\section{Computers and IT}

Table 13. Computers and IT policies

\begin{tabular}{lllll}
\hline Policy ID & NPO Cat 1: & NPO Cat 2: & NPO Cat 3: & NPO Cat 4: \\
& Smallest & Medium & Large & Extra-Large \\
\hline IT-100 Data Integrity & $\checkmark$ & $\checkmark$ & $\checkmark$ & $\checkmark$ \\
IT-110 Internet and Cell Use Policy & & $\checkmark$ & $\checkmark$ & $\checkmark$ \\
IT-120 Email Policy & $\checkmark$ & $\checkmark$ & $\checkmark$ & $\checkmark$ \\
\hline
\end{tabular}

This section contains the policies that govern the acceptable use of company provided IT equipment (Copedia 2012). The previous Study on Non-Profit Organizations in South Carolina shows that 99 percent of respondents use email as a basis of corresponding for their organization. Also, 89 percent of the respondents use social networking websites as a form of outreach (Maguire 2012). Due to the fact that the use of technology has such a prominent role in the NPO world, it is vital that these organizations implement policies governing the use of company provided computers, internet, and cell phones. SCANPO's Guiding Principles that apply include Legal \& Ethical Accountability as well as Information Management. These Guiding Principles speak about how nonprofits are obligated to display high levels of ethical behavior, accountability, and transparency (SCANPO 2012). The National Council of Nonprofits' Effective Governance section applies, specifically Principle 8 (Panel on the Nonprofit Sector 2007). Blue Avocado's Physical Controls section recommends that computers be locked and passwords employed (Ho 2010). 


\section{Small NPOs}

To ensure that only authorized persons have direct access to computerized documents and funds it is essential that NPOs have policies surrounding data integrity, email, and internet and cell phone use. The IT-100 Data Integrity policy is recommended for all NPOs. Within this policy, it clearly states basic structures for NPOs such as division of duties, disaster controls, and proper procedure surrounding data security. The IT-120 Email Policy is also recommended for all NPOs. This policy states there needs to be a clear boundary between personal and business use, controls surrounding authority and practices, as well as a retention policy. Due to the nature of the material that may be addressed in emails such as financials and contacts, this email policy for all NPOs is recommended as well. An email should be treated as any other form of communication and the material within it should not only be professional but also secured. Including this policy in all NPO's procedures can prevent secure information from reaching unintended users as well as prevent the misuse of an organization's resources.

Medium, Large, and Extra-Large NPOs

The last policy in this section is IT-110 Internet \& Cell Use Policy. It is recommended that this policy be implemented for medium NPOs and larger. This policy governs the use of company cell phones and internet for personal use. Employees of small NPOs will potentially be using their personal computers and cell phones due to the small NPO's limited resources. However, if a small NPO provides these resources to employees, then this policy should be implemented for small NPOs as well.

\section{Business Development}

Table 14. Business development policies

\begin{tabular}{lllll}
\hline Policy ID & NPO Cat 1: & NPO Cat 2: & NPO Cat 3: & NPO Cat 4: \\
& Smallest & Medium & Large & Extra-Large \\
\hline Sales-100 Sales Manual & & & $\checkmark$ & $\checkmark$ \\
Sales-110 Sales Process Flowchart & & $\checkmark$ & $\checkmark$ & $\checkmark$ \\
Sales-200 Orders \& Contract & & $\checkmark$ & $\checkmark$ & $\checkmark$ \\
Sales-210 Point of Sales and Cash Drawers & & $\checkmark$ & $\checkmark$ & $\checkmark$ \\
Sales-250 Fundraising Policy & $\checkmark$ & $\checkmark$ & $\checkmark$ & $\checkmark$ \\
Sales-260 Gift \& Donations Policy & $\checkmark$ & & $\checkmark$ & $\checkmark$ \\
Sales-400 Sales Returns Flow Chart & & & & $\checkmark$ \\
\hline
\end{tabular}

Business Development policies align the NPO's sales and fundraising strategies with the organization's mission and vision. These policies ensure that the intentions of the donors are fulfilled while complying with laws and regulations. The Copedia Manual defines fundraising as "the act of soliciting gifts and donations for the tax-exempt purposes of the organization" (Copedia 2012). The Study on Non-Profit Organizations indicated that $59 \%$ of NPOs in South Carolina have a Fundraising Committee (Maguire 2012). SCANPO's Guiding Principles Financial Management \& Stewardship and Fundraising, as well as the National Council of Nonprofits' category on Responsible Fundraising contain guidance on best practices for an NPO's fundraising activities (SCANPO 2012; Panel on the Nonprofit Sector 2007).

\section{Small NPOs}

According to Blue Avocado, it is important for very small nonprofits to have a cash policy in place. In doing this, the organization will be able to ensure that each person is accountable for their actions (Ho 2010). SCANPO also addresses the importance of establishing a cash policy in its Guiding Principle Financial Management \& Stewardship (SCANPO 2012). For small NPOs, these activities are addressed in the Assets section via Assets 410 Cash Management.

In order to comply with Form 1771, all NPOs are required by law to adopt Sales-250 Fundraising Policy (IRS 2011). This policy contains the disclosure rules required of NPOs that receive charitable contributions (Copedia 2012).

Based upon the best practices put forth by SCANPO, the National Council of Nonprofits, and Blue Avocado, it is recommended that all NPOs also install Sales-260 Gift \& Donations Policy and if possible, a Fundraising Committee. According to the 2011 survey, 35\% of NPOs have not yet established a gift policy (Maguire 2012). This policy addresses that need. The IRS requires that contributions be used for the purposes consistent with the donor's intent, whether as described in the relevant solicitation materials or as specifically directed by the donor (IRS 2011). 


\section{Medium NPOs}

According to SCANPO's Best Practices an order and contract policy should be included to comply with Guiding Principles Financial Management \& Stewardship and Operations \& and Evaluations. For this reason, it can be concluded that the Sales-200 Orders and Contracts policy be recommended for all medium sized NPOs. A sales order and contracts policy should include a purchasing process that tracks purchases from request through payment as well as an organizational chart depicting who has authority to allocate funds. As the organization continues to grow, it is very important to include this policy in all other categories of NPOs in order to maximize funds that can be distributed. Also, given that fundraising activities will likely increase in complexity, Sales-210 Point of Sales and Cash Drawer Policy is also recommended for the medium NPO to supplement the Cash Management policy utilized by small NPOs.

\section{Large and Extra-Large NPOs}

Sales-100 Sales Manual, Sales-110 Sales Process Flowchart, and Sales-400 Sales Returns Flowchart are recommended for large and extra-large NPOs. These policies allow for a fully developed sales manual that is aligned with the NPO's mission and vision. Topics addressed include product positioning, branding, product comparisons, selling strategies, and marketing tools (Copedia 2012).

\section{Project Management}

Table 15. Project management policies

\begin{tabular}{lllll}
\hline Policy ID & $\begin{array}{l}\text { NPO Cat 1: } \\
\text { Smallest }\end{array}$ & $\begin{array}{l}\text { NPO Cat 2: } \\
\text { Medium }\end{array}$ & $\begin{array}{l}\text { NPO Cat 3: } \\
\text { Large }\end{array}$ & $\begin{array}{l}\text { NPO Cat 4: } \\
\text { Extra-Large }\end{array}$ \\
\hline $\begin{array}{l}\text { Proj-Grants-100 Grant } \\
\quad \text { Management }\end{array}$ & & $\checkmark$ & $\checkmark$ & $\checkmark$ \\
$\begin{array}{l}\text { Proj-Grants-200 } \\
\text { Financial Administration }\end{array}$ & & & \\
$\begin{array}{l}\text { Proj-Grants-210 Draw-downs and Reimbursements } \\
\text { Proj-Grants-400 Grant Financial Reporting }\end{array}$ & $\checkmark$ & $\checkmark$ & $\checkmark$ \\
$\begin{array}{l}\text { Proj-Grants-450 Grant Monitoring and Reporting } \\
\text { Performance }\end{array}$ & $\checkmark$ & $\checkmark$ & $\checkmark$ & $\checkmark$ \\
& & $\checkmark$ & $\checkmark$ & $\checkmark$ \\
\end{tabular}

Nonprofits enter grant agreements with government agencies, private foundations, and donors. It is necessary to know the terms that are established by the awarded grant in order to be successful in obtaining grants. According to the Study on Non-Profit Organizations in South Carolina, 58\% of respondents seek foundation grants while 38\% seek government grants (Maguire 2012). The following recommended policies tie in with SCANPO's Guiding Principle Financial Management \& Stewardship, which states the importance of the NPO knowing where the grant came from, understanding the terms of the grant, and supervising where the money is going (SCANPO 2012). These policies also fall under the National Council of Nonprofits'Legal Compliance and Public Disclosure Principle 6, which enables the NPO to have a system of checks and balances for the protection of any grants received (Panel on the Nonprofit Sector 2007).

\section{Small NPOs}

Two policies, Proj-Grants-400 Grant Financial Reporting policy and Proj-Grants-450 Grant Monitoring and Reporting Performance, are recommended for all NPOs, assuming the NPO relies on grant revenue. These policies highlight compliance with financial reporting, monitoring, and reporting requirements of funding agencies and their programs.

\section{Medium NPOs}

Policies recommended for medium and larger NPOs include two additional policies. Proj-Grant-100 Grant Management establishes policies for the administration and management of grants. This policy details definition of roles, acceptance of awards, internal audit of grants, and grant coordination. Proj-Grant-200Financial Administration establishes standards for proper financial administration as required by the NPO's Board and funding sources. This policy assists with financial reporting, internal control, and source documentation.

\section{Large and Extra-Large NPOs}

For large and extra-large NPOs, it is recommended that Proj-Grant-210Grant Draw-down and Reimbursement Policy be implemented. This policy helps establish basic standards for draw-downs and reimbursements which 
aid the NPO in receiving grant revenues as early and as often as possible. It provides for internal procedures, authorization, and basic standards.

Additional Information on Federal awards and grants:

Applying SCANPO's Guiding Principle Legal \& Ethical Accountability, there are certain policies that are recommended for all sizes when working with Federal awards or grants. These policies also fall under the National Council of Nonprofits' Legal Compliance and Public Disclosure Principle 1. The policies are: Proj-Grants-220 Allowable Costs; Proj-Grants-230 Cost Principles and Basic Considerations; Proj-Grants-231 Direct Costs; Proj-Grants-232 Indirect Cost; Proj-Grants-233 Indirect Cost Allocation; Proj-Grants-234 Indirect Cost Rate Approval; and Proj-Grants-235 Selected Items of Cost. These policies guide the nonprofit to accomplish compliance with OMB Cost Principles as detailed in OMB Circular A-122. The Proj-Grants-460 Records Management policy is also recommended. Lastly, Copedia lists various "what if" and "how to" items in the Table of Contents that may come up in grant management (Copedia 2012). These items should also be followed no matter the NPO size because of the many regulations that apply to grants.

\section{Human Resources, Employees, and Payroll}

Table 16. Human resources, employees, and payroll policies

\begin{tabular}{lllll}
\hline Policy ID & NPO Cat 1: & NPO Cat 2: & NPO Cat 3: & $\begin{array}{l}\text { NPO Cat 4: } \\
\text { Extra-Large }\end{array}$ \\
\hline EHB-100 Employee Handbook Intro. & Small & $\checkmark$ & Medium & Large \\
EHB-110 General Employment Policies & $\checkmark$ & $\checkmark$ & $\checkmark$ & $\checkmark$ \\
EHB-115 Expense Reimbursement & $\checkmark$ & $\checkmark$ & $\checkmark$ & $\checkmark$ \\
EHB-116 Travel Policy & $\checkmark$ & $\checkmark$ & $\checkmark$ & $\checkmark$ \\
EHB-130 Compensation and Pay Policies & $\checkmark$ & $\checkmark$ & $\checkmark$ & $\checkmark$ \\
EHB-130 Employee Benefits & $\checkmark$ & $\checkmark$ & $\checkmark$ & $\checkmark$ \\
EHB-140 Employee Safety and Health & $\checkmark$ & $\checkmark$ & $\checkmark$ & $\checkmark$ \\
EHB-150 Absences and Leaves & $\checkmark$ & $\checkmark$ & $\checkmark$ & $\checkmark$ \\
EHB-155 Holidays & $\checkmark$ & $\checkmark$ & $\checkmark$ & $\checkmark$ \\
EHB-160 Personal Conduct and Corrective & $\checkmark$ & $\checkmark$ & $\checkmark$ & $\checkmark$ \\
Action Policy & $\checkmark$ & $\checkmark$ & $\checkmark$ & $\checkmark$ \\
EHB-170 Employee Communications & $\checkmark$ & $\checkmark$ & $\checkmark$ & $\checkmark$ \\
EHB-180 Acknowledgement Forms & $\checkmark$ & $\checkmark$ & $\checkmark$ & $\checkmark$ \\
EHB-181 Workers Compensation & $\checkmark$ & $\checkmark$ & $\checkmark$ \\
Acknowledgement & & & & $\checkmark$ \\
\hline
\end{tabular}

Copedia's Employee Manual contains all policies relevant to managing human resources. Examples include Compensation and Pay Policies, Employee Benefits, Expense Reimbursement, Workers Compensation, and a Personal Conduct and Corrective Action Policy. Using the information received from the 2011 Study on Non-Profit Organizationsin South Carolina survey, it was found that only 21\% of responding South Carolina NPOs set up a human resource committee, and only $10 \%$ set up a compensation committee (Maguire 2012). SCANPO discusses the importance of Human Resources to all NPOs in their Guiding Principles regarding Legal \& Ethical Accountability and Human Resources (SCANPO, 2012). The National Council for Nonprofits' best practices also addresses human resources through its Legal Compliance and Public Disclosures section, specifically Principles 1 and 6. The National Council for Nonprofits also strongly advises NPOs to adopt an employee manual (Panel on the Nonprofit Sector 2007). The Copedia employee manual can help satisfy this recommendation by setting up the needed employee guidelines. Smaller to medium NPOs typically do not have an actual HR department, but still must incorporate these human resource procedures to ensure legal compliance. Blue Avocado suggests that NPOs' boards establish a human resource committee if applicable to help with setting up the human resource procedures (Ho 2010). Blue Avocado then lays out guidelines on Setting the Control Environment, which incorporates the human resource division of the NPO. The Copedia employee handbook satisfies each of these requirements.

Compliance with employee standards on both the state and federal levels is an issue for NPOs of all sizes. The legislation surrounding worker rights applies to both paid employees and volunteers. Examples of applicable laws include The Volunteer Protection Act of 1997, The Family and Medical Leave Act, and The Americans with Disabilities Act. The recommendation is that the adoption of the entire Copedia employee manual be implemented by NPOs of all sizes. This will put in place the compliance needed for the NPO to function in 
regards to human resources.

\section{Safety, Health, and Environment}

Table 17. Safety, health, and environment policies

\begin{tabular}{lllll}
\hline Policy ID & NPO Cat 1: & NPO Cat 2: & NPO Cat 3: & NPO Cat 4: \\
& Smallest & Medium & Large & Extra-Large \\
\hline OSHA Poster & $\checkmark$ & $\checkmark$ & $\checkmark$ & $\checkmark$ \\
Safety Warnings & $\checkmark$ & $\checkmark$ & $\checkmark$ & $\checkmark$ \\
Safety System & $\checkmark$ & $\checkmark$ & $\checkmark$ & $\checkmark$ \\
Reporting System & $\checkmark$ & $\checkmark$ & $\checkmark$ & $\checkmark$ \\
Industry Specific & Possibly & Possibly & Possibly & Possibly \\
\hline
\end{tabular}

The position on safety and health from SCANPO, the National Council for Nonprofits and Blue Avocado is to follow the applicable laws of the local, state, and federal government. These laws are largely controlled and regulated by the Occupational Safety and Health Administration (OSHA). Each state could enforce its own OSHA state plan, but if not, all states are covered by the federal OSHA plan. South Carolina has its own federally approved state OSHA safety and health plan.

There are a few policies that are required by OSHA for any business regardless of the number of employees. The first of which is OSHA Handbooks, Manuals, and Poster forms that must be posted and available in the employee break room. The next requirement is employee safety warnings which are brightly colored stickers or signs that point out any safety hazards that may be harmful to employees, emergency exits, and emergency equipment. A clear example of this is brightly colored exit signs, working fire alarms, and first aid kits. Another requirement of OSHA that will affect all NPO sizes is an accident reporting system. Any business with more than ten employees must keep injury and illness records with OSHA and must post them at the end of every year. If an NPO has less than ten employees, it only has to report to OSHA if a death occurs on site or if there are more than three employees hospitalized. In either case, it is recommended that an NPO of any size have an accident reporting system which outlines the procedures to follow in the event of serious injury or death along with any forms or authorities that should be notified (South Carolina Department of Labor 2012).

Currently, South Carolina does not require employers to establish a Safety and Health system, but SC OSHA has published best practices guidelines to help employers prevent work related injuries and illnesses. SC OSHA does recognize that having an effective safety system in place has reduced the number of work related injuries and illnesses (South Carolina Department of Labor 2012).

For the small NPOs with two or less employees, it is recommended that they have some sort of safety policy and guidelines in place to protect themselves from any employee negligence. A copy of this policy should be given to each employee at the time of hiring. As an NPO moves from the small to medium category, it should start to adopt additional policies and guidelines to accommodate the additional employees. For example, forming a Safety and Health committee is a recommendation that could be realized within this NPO size. An optimal committee structure is comprised of one employee, one member of management, and one member from the board of directors. This ensures that everyone from the top down is involved with safety policies implemented within the NPO. The responsibility of this committee will be to handle all safety and health issues and policies (South Carolina Department of Labor 2012).

Lastly, there are a few safety and health policies that are more industry specific than general. First of which is the policy on safety orientation. If for example you have formed an NPO with the purpose of providing natural disaster relief by replacing and repairing roofing, then a policy on conducting safety orientations for new employees should be implemented.The next policy is concerned with accidental environmental spill reporting. If an NPO deals with any environmentally dangerous substances, for example if the NPO's activities include transporting recycled oil, then they must add this report to their accident reporting system. The last industry specific policy deals with HazAware. HazAware is any employee protective clothing or equipment needed to handle hazardous materials along with the proper disposal of those materials. For example, if an NPO is formed to give flu shots to the elderly, then employees must be provided surgical gloves, needles, and the proper disposal containers for used needles (South Carolina Department of Labor 2012). 


\section{Internal Controls and Best Practices}

Table 18. Internal controls and best practices policies

\begin{tabular}{|c|c|c|c|c|}
\hline Policy ID & $\begin{array}{l}\text { NPO Cat 1: } \\
\text { Smallest }\end{array}$ & $\begin{array}{l}\text { NPO Cat 2: } \\
\text { Medium }\end{array}$ & $\begin{array}{l}\text { NPO Cat 3: } \\
\text { Large }\end{array}$ & $\begin{array}{l}\text { NPO Cat 4: } \\
\text { Extra-Large }\end{array}$ \\
\hline IC-100Internal Control Policy & $\checkmark$ & $\checkmark$ & $\checkmark$ & $\checkmark$ \\
\hline IC-110 Internal Control Evaluation Tool & $\checkmark$ & $\checkmark$ & $\checkmark$ & $\checkmark$ \\
\hline IC-120 Environment & $\checkmark$ & $\checkmark$ & $\checkmark$ & $\checkmark$ \\
\hline IC-130 Activities & $\checkmark$ & $\checkmark$ & $\checkmark$ & $\checkmark$ \\
\hline IC-140 Risk & $\checkmark$ & $\checkmark$ & $\checkmark$ & $\checkmark$ \\
\hline IC-150 Info and Communication & $\checkmark$ & $\checkmark$ & $\checkmark$ & $\checkmark$ \\
\hline IC-160 Monitoring & $\checkmark$ & $\checkmark$ & $\checkmark$ & $\checkmark$ \\
\hline IC-200 Financial Reporting & & & & $\checkmark$ \\
\hline IC-210 Revenue Cycle & & & $\checkmark$ & $\checkmark$ \\
\hline $\mathrm{IC}-220 \mathrm{~A} / \mathrm{R}$ & & & $\checkmark$ & $\checkmark$ \\
\hline IC-300 Expenditure Cycle & & & $\checkmark$ & $\checkmark$ \\
\hline IC-310 Purchasing & & & & $\checkmark$ \\
\hline IC-320 A/P & & & $\checkmark$ & $\checkmark$ \\
\hline IC-330 Checks & & $\checkmark$ & $\checkmark$ & $\checkmark$ \\
\hline IC-350 Payroll and HR & & $\checkmark$ & $\checkmark$ & $\checkmark$ \\
\hline IC-400 Assets & & & $\checkmark$ & $\checkmark$ \\
\hline IC-410 Cash & & $\checkmark$ & $\checkmark$ & $\checkmark$ \\
\hline IC-450 Receiving & & & $\checkmark$ & $\checkmark$ \\
\hline IC-500 Internal Control Reviews & & $\checkmark$ & $\checkmark$ & $\checkmark$ \\
\hline IC-550 Data Integrity & & & & $\checkmark$ \\
\hline IC-600 Markets and Customers & & & & $\checkmark$ \\
\hline IC-610 Sales & & & & $\checkmark$ \\
\hline IC-700 Project Management & & & & $\checkmark$ \\
\hline IC-710 Job Costing & & & & $\checkmark$ \\
\hline IC-750 Safety & & $\checkmark$ & $\checkmark$ & $\checkmark$ \\
\hline IC-800 Retail & & & & $\checkmark$ \\
\hline
\end{tabular}

Internal Controls are used to promote orderly and efficient operations. They are also put in place to safeguard resources against errors and cases of fraud as well as to promote compliance with regulations and statutes. Through implementation of internal controls NPOs should produce quality products and services, as well as develop and maintain reliable financial and management data. With regards to NPOs there are numerous controls that must be established throughout the life of the company, but it can be difficult for companies with one to two people to implement all of these policies simultaneously. The smallest category must establish a base level of polices that set the control environment. From the beginning, there must be policies in place that are followed by everybody without exception. Top management can set an ethically responsible tone that shows all procedures must be followed from the top down.

\section{Small NPOs}

According to Blue Avocado, a control environment must be established from the start. This environment is similar to what non-public companies call a "SOX-like environment," referring to the regulations and compliance controls of public companies set forth by the Sarbanes-Oxley Act of 2002. Although private companies are not required to follow SOX, many companies are trying to adhere to these policies in order to have better standing with stakeholders. All the base policies will be put in place to establish a control environment, which will enable additional policies to be added on as the company grows. Each policy dealing with the overall environment of the company includes IC-100Internal Control Policy, IC-110 Internal Control Evaluation Tool, IC-120 Environment, IC-130 Activities, IC-140 Risk, IC-150 Information and Communication, and IC-160 Monitoring. All of these policies are general policies that must be instituted from the beginning to establish a base level of controls.

\section{Medium NPOs}

Moving into the medium category, high risk items need to be addressed to try to limit the liability of the company. Controls over cash and checks should be implemented by medium size NPOs. Legal liability is also a concern as the NPO grows. It is recommended that all policies regarding Safety, Payroll, and Human Resources 
are complete in order to protect the NPO going forward and lower liability and risk. Lastly, it is recommended that full Internal Control Reviews be implemented to begin to assess and review the NPO's internal controls as it continues to grow. Policies recommended include IC-330 Checks, IC-350 Payroll and HR, IC-410 Cash, IC-500 Internal Control Reviews, and IC-750 Safety.

Large NPOs

NPOs in the large category will have transitioned to the accrual basis of accounting. It is recommended that all accounting controls that would fall under the accrual basis be fully implemented to match the accounting basis the NPO would be using. These categories include Revenue, AR, Expenditure, AP, and Assets. All of these controls must be fully implemented due to the shift to the accrual basis. Policies recommended include IC-210 Revenue Cycle, IC-220 AccountsReceivable, IC-300 Expenditure Cycle, IC-320 Accounts Payable, IC-400 Assets, and IC-450 Receiving.

\section{Extra-Large NPOs}

At the extra-large NPO category, all previous controls will be in place, and all other controls will be fully implemented. The policies include Financial Reporting, Purchasing, Receiving, Data Integrity, Markets and Customers, Sales, Project Management, Job Costing, and Retail. There are adequate controls in the individual categories to satisfy overall risk until these control policies are fully implemented at the extra-large level. Policies recommended include IC-200 Financial Reporting, IC-550 Data Integrity, IC-600 Markets and Customers, IC-610 Sales, IC-700 Project Management, and IC-710 Job Costing.

The overall goal when establishing internal controls is to initially create a SOX- like environment to establish a solid base level of control within the NPO. As the NPO grows the risk of each policy is assessed to determine what size is necessary for the company to adopt the full control. Smaller NPOs should not be burdened with policies that are neither necessary nor required, but it is necessary to protect the company from fraud and legal risks. This should create a picture of how gradual implementations of full controls can be done efficiently and effectively over the life of the NPO.

\section{Summary of Findings}

An analysis of Copedia's Non Profit Edition policies and procedures manual template library yielded the following results:

Using the assembled policies and procedures manuals in this paper, NPOs of all sizes can achieve best practices suggested by SCANPO's Guiding Principles and Best Practices, third edition; the National Council of Nonprofits' Principles for Good Governance and Ethical Practice; and Blue Avocado's Five Internal Controls for the Very Small Nonprofit.

22 policies are required by law for all NPOs, regardless of size.

34 policies are recommended for small NPOs. Combined with those required by law, the total number of policies that will allow a small NPO to achieve best practices without being encumbered by unnecessary polices is 56 .

65 policies are recommended for medium NPOs. Combined with those required by law, 87 policies will allow a medium NPO to achieve best practices.

87 policies are recommended for large NPOs. Combined with those required by law, 109 policies will allow a large NPO to achieve best practices.

102 policies are recommended for extra-large NPOs. Combined with those required by law, 124 policies will allow an extra-large NPO to achieve best practices.

The Unified Chart of Accounts (UCOA) is recommended for all firms. Smaller NPOs can utilize our recommended subset of accounts, then add UCOA accounts as they grow. UCOA provides instructions for existing NPOs to transition from their existing chart of accounts to UCOA.

The objective of this paper is to assemble a stepwise menu of policies and procedures for Nonprofit Organizations (NPOs) in South Carolina. This stepwise menu of policies and procedures will be used to assist NPOs of all sizes in South Carolina achieve best practices. Working in collaboration with The Chapin Foundation, The Waccamaw Foundation, and the South Carolina Association of Nonprofit Organizations (SCANPO), the output of this project will assist NPOs in obtaining affordable audits and reviews, utilizing cost effective techniques when creating a policies and procedures manual, and adding to the policies and procedures manual as they grow. Achieving compliance with best practices for financial accountability, fundraising, and board governance, the output of this project facilitates the link between philanthropic leadership, charitable 
resources, and civic influence with community needs and opportunities.

\section{References}

Albrecht, W. S., Albrecht, C. O., Albrecht, C. C., \& Zimbelman, M. F. (2012). Fraud Examination. Mason, OH: South-Western.

Blackwood, A., \& Roeger, K. L. (2012, October 3). Revoked: A Snapshot of Orginazations that Lost their Tax Exempt Status. Retrieved from http://www.urban.org/publications/412386.html

Brick, A. (2012). Strategies for reducing Operating Costs. Managing Partner of Cost Management Solutions. Retrieved from http://www.minnesotanonprofits.org/nonprofit-resources/financial-management/budgeting/strategies-for-red ucing-operating-costs

Carpenter, M., \& Sanders, G. (2008). Strategic Management: Concepts and Cases (2nd ed.). New York: Prentice Hall.

Compass Point. (2012, October 3). Nonprofit Fiscal Policies \& Procedures: A Template and Guide. Retrieved from http://www.compasspoint.org/sites/default/files/documents/Guide\%20to\%20Fiscal\%20Policies\%20and\%20 $\% 20$ Procedures.pdf

Connors, D. (2011, October 12). Accounting Procedures Manual Template. Retrieved from $\mathrm{http}: / /$ www.blueavocado.org/content/accounting-procedures-manual-template

Free Management Library. (2012). Computer and Network Usage Policies. Retrieved from http://managementhelp.org/computers/policies.htm

Ho, C. (2010, January 6). CPA. Five Internal Controls for the Very Small Non Profit. Daly City, CA, USA. Retrieved from http://www.blueavocado.org/content/five-internal-controls-very-small-nonprofit

Hoover, S. (2010). Copedia: A Standard Framework for the Management of Businesses and Non-Profits. Endeavor Inc. Washington, D.C. Retrieved from http://www.copedia.biz/category_s/18.htm

Internal Revenue Service. (2012, October 22). Charitable Contributions: Substantiation and Disclosure Requirements. Retrieved from www.irs.gov/pub/irs-pdf/p1771.pdf

Internal Revenue Service. (2012, October 22). Form 990 Series- Which Forms Do Exempt Organizations File. Retrieved from http://www.irs.gov/Charities-\&-Non-Profits/Form-990-Series-Which-Forms-Do-Exempt-Organizations-File $\% 3 \mathrm{~F}-($ Filing-Phase-In)

LawForChange. (2012). Federal Laws regarding Employment. Retrieved from http://www.lawforchange.org/NewsBot.asp?MODE=VIEW\&ID=3163

Levis, W. C., \& Sumariwalla, R. D. (2000). Unified Financial Reporting System for Not-for-Profit Organizations: A comprehensive Guide to Unifying GAAP, IRS Form 990 and Other Financial Reports Using a Unified Chart of Accounts. Retrieved from http://www.josseybass.com/WileyCDA/WileyTitle/productCd-0787952133.html

Maguire, K. (2012). Survey of Accounting, Auditing, and Governance Practices of Non-Profit Organizations in South Carolina: A Research Service Learning Project. Business Management Dynamics, 2(2), 33-60.

Masaoka, J. (2010, July 6). Nonprofit Conflict of Interest: A 3-Dimensional View. Retrieved from http://www.blueavocado.org/content/nonprofit-conflict-interest-3-dimensional-view

National Center for Charitable Statistics. (2012). UCOA QuickBooks Files. Unified Chart of Accounts. Retrieved from http://nccs.urban.org/projects/ucoa.cfm\#Spreadsheet

National Center for Charitable Statistics. (2012). UCOA Toolkit. Unified Chart of Accounts. Retrieved from http://nccs.urban.org/projects/ucoa.cfm\#Spreadsheet

National Center for Charitable Statistics. (2012). UCOA Version 3 Keyword Lookup Spreadsheet. Unified Chart of Accounts. Retrieved from http://nccs.urban.org/projects/ucoa.cfm\#Spreadsheet

National Council of Nonprofits. (2012). Ethics and Accountability in the Nonprofit Sector. Retrieved from $\mathrm{http} / / / \mathrm{www}$.councilofnonprofits.org/resources/resources-topic/ethics-accountability

National Council of Nonprofits. (2012). Principles and Practices. Retrieved from 
http://www.councilofnonprofits.org/resources/resources-topic/principles-and-practices

Nonprofit Risk Management Center. (2012). Protecting Assets with Sound Internal Controls. Retrieved from http://www.minnesotanonprofits.org/nonprofit-resources/financial-management/budgeting/protecting-assets -with-sound-internal-controls

Nonprofit Risk Management Center. (2012, September 12). Protecting Assets with Sound Internal Controls. Retrieved from http://www.minnesotanonprofits.org/nonprofit-resources/financial-management/budgeting/protecting-assets -with-sound-internal-controls

NonProfitExpert.com. (2012). Ways NonProfits Can Save. Retrieved from http://www.nonprofitexpert.com/saving_money.htm

O’Malley, P. A. (2009, March 30). Reporting and Operations: Internal Controls for Small Organizations. Retrieved from http://www.nonprofitaccountingbasics.org/reporting-operations/fixed-assets

Office of Management and Budget. (2012). Circular A-110 Revised 11/19/93 As Further Amended 9/30/99. Retrieved from http://www.whitehouse.gov/omb/circulars_a110/

OfficeSkills.Org. (2012). Office Procedures. Retrieved from http://officeskills.org/office-procedures.html

Panel on the Non Profit Sector. (2007). Principles for Good Governance and Ethical Practice: A Guide for Charities and Foundations. Washington, DC.

Panel on the Non Profit Sector. (2012). New Workbook Expands On Principles for Good Governance. Retrieved from http://nccs.urban.org/projects/ucoa.cfm\#Spreadsheet

PricewaterhouseCoopers. (1999). Accounting Policies and Procedures for Early Stage Companies. Retrieved from http://startupjunkies.org/acct-policies.pdf

Ratcliffe, T. A. (2009, September). Understanding Internal Control and Internal Control Services. Journal of Accountancy.

Retrieved

from http://www.journalofaccountancy.com/Issues/2009/Sep/White+Paper+Understanding+Internal+Control+an $\mathrm{d}+$ Internal+Control+Services.htm

Reck, J. L., Lowensohn, S. L., \& Wilson, E. R. (2013). Accounting for Governments \& Nonprofit Entities (16th ed.). New York: McGraw-Hill Irwin.

Sarbanes-Oxley Act of 2002, Pub. L. No. 107-204, 116 Stat. 745. (2002).

SCANPO. (2012). Nonprofit Membership Rates. Retrieved from http://www.scanpo.org/learn-and-join/member-services-and-levels/

SCANPO. (2012, October 3). Guiding Principles \& Best Practices (3rd ed.). Retrieved from $\mathrm{http}: / / \mathrm{www}$.scanpo.org/3rd-edition/guiding-principles/

Securities and Exchange Commission. (1999, December 3). Staff Accounting Bulletin No. 101- Revenue Recognition in Financial Statements. Retrieved from http://www.sec.gov/interps/account/sab101.htm

Securities and Exchange Commission. (2003, December 17). Staff Accounting Bulletin No. 104. Retrieved from http://www.sec.gov/interps/account/sab104rev.pdf

South Carolina Department of Labor. (2012) OSHA Checklist. Retrieved from http://www.scosha.llronline.com/index.asp?file=checklists.htm

The Nonprofit Times. (2012). Small Shops Need Procedures in Place. Retrieved from http://www.thenonprofittimes.com/article/detail/small-shops-need-procedures-in-place-2668

United States Department of Labor. (2012). Occupational Safety \& Health Administration. Retrieved from http://www.osha.gov

Vermont Department of Finance and Management. (2012). Internal Control FAQ. Retrieved from http://finance.vermont.gov/faq/ic_faq 


\section{Appendix A: Unified Chart of Accounts Resources}

Recommended UCOA accounts for small, medium, large, and extra-large NPOs:

Microsoft Excel workbook created by Coastal Carolina University's Fall 2012 Advanced Auditing class. Please contact Dr. Karen Maguire at kmaguire@coastal.edu.

Accounts Dictionary:

http://nccs.urban.org/projects/ucoa.cfm\#Spreadsheet

Open the file named UCOA ver.3 Keyword Lookup Spreadsheet

Implementation of UCOA:

http://nccs.urban.org/projects/ucoa.cfm\#Spreadsheet

Open the file named UCOA QuickBooks Files and UCOA Toolkit

Switching from an Existing System to UCOA:

http://nccs.urban.org/projects/ucoa.cfm\#Spreadsheet

Open the file named UCOA ver.3 Keyword Lookup Spreadsheet

Text Providing Complete Overview of UCOA and Chart of Accounts:

http://www.josseybass.com/WileyCDA/WileyTitle/productCd-0787952133.html

\section{Copyrights}

Copyright for this article is retained by the author(s), with first publication rights granted to the journal.

This is an open-access article distributed under the terms and conditions of the Creative Commons Attribution license (http://creativecommons.org/licenses/by/3.0/). 